\title{
Q \\ Helps with the thermal diagnosis of the building : Detection of defects of insulation by stimulated infra-red thermography
}

\author{
by Jean Charles Candoré*, Jean Luc Bodnar*, Antoine Szeflinski*, Laurent lbos**, Stefan Datcu**, \\ Yves Candau**, Simone Mattéi ${ }^{* * *}$, Jean-Claude Frichet ${ }^{* * *}$ \\ *Laboratoire d'Energétique et d'Optique, UFR Sciences Exactes et Naturelles, BP 1039, 51687 Reims cedex 02, \\ France \\ ${ }^{* *}$ CERTES, Université Paris 12 Val de Marne, 61 av. du Gal de Gaule, 94010 Créteil cedex, France \\ *** LTM, Université de Bourgogne, IUT du Creusot, 71200 Le Creusot cedex, France \\ ${ }^{* * * *}$ EDF R\&D, Les Renardières, Ecuelles, Moret sur Loing, France
}

\begin{abstract}
In this work, we present the study of the possibilities of the stimulated IR thermography as helps with the detection of defects of insulation in building. The process of insulation studied was selected among most representative of the French market. It is about an insulating complex made up of a plate of plaster facing on which is fixed expanded polystyrene. Among all the possible defects of insulation, we chose to study those which are most usually met in France. Thus we show that the method allows the detection of defects generated by a complete absence of insulator (filled in all or partly by plaster), defects due to the partial suppression of insulator, filled by plaster, to mask a transport of fluid and finally of defects generated by a variation thickness of insulator.
\end{abstract}

\section{Introduction}

Following the oil crises of the Seventies and with the crisis of the energy which was followed from there, a national policy of saving energy was implemented. This policy was made feel especially in the field of the building where more strict regulations as for the insulation were enacted in order to avoid a wasting due to the energy losses of constructions. This policy of saving energy always continues today, since very recently, in November 2006, it was made obligation with any salesman of housing to carry out a thermal balance at the time of the resale.

The purpose of these standards, established by the Scientific and Technical Center of the Building industry (C.S.T.B) and published in Technical Documents Unified (D.T.U) such as the rules Th K, Th BV, Th GV,..., now known under name RT 2005 with the calculation of the Ubat coefficient, are to regulate materials to be used as well as the way in which they must be posed. These documents also make it possible to quantify the losses, the contributions and the energy needs of the buildings. Compliance or not with these rules will then vary, in strong proportions, the feeling of comfort and especially energy consumptions.

However on the ground, the application of these rules is sometimes doubtful because of negligence or of the ignorance of the problem. It is then very difficult, by a traditional inspection, to locate the possible defects of insulation since the insulators are, in practice, always covered with various elements of completion. On the other hand a thermal analysis of the behavior of the surface of material is possible because the results obtained will vary according to the composition of the studied sample. The choice was then naturally made on infra-red thermography since it makes it possible to draw up a wide map of temperature of the inspected elements. Moreover conditions of use of this method are still very strict. Indeed, this technique, under the static conditions where it is implemented currently, request a heat gradient relatively important and durable between the interior and the outside of the studied building, which notably limits its area of activity (the analysis by static infra-red thermography is almost not possible in practice, apart from wintry times). This is why, in this study, we will try to examine the possibilities of the stimulated infra-red thermography as helps with the detection of defects of insulation in the field of the building. The process of insulation studied was selected among most representative of the French market. It is about an insulating complex made up of a plate of plaster facing on which is fixed expanded polystyrene. Among all the possible defects of insulation, we chose to study those which are most usually met in France. . Thus we show that the method allows the detection of defects generated by a complete absence of insulator (filled in all or partly by plaster), defects due to the partial suppression of insulator, filled by plaster, to mask a transport of fluid and finally of defects generated by a variation thickness of insulator.

\section{Advantages and limitations of passive IR thermogrphy in the detection of building walls insulation defaults}

The main advantage of using passive IR thermography is that this method only requires the use of an IR camera. No additional experimental set-up is needed. The panel of portable IR cameras developed recently for diagnosis inspections is now important. Moreover, new devices are available at a low price and the thermal resolution of he simplest cameras is near 0.1 to $0.2^{\circ} \mathrm{C}$, which is sufficient to detect temperature variations on a building due to insulation defaults. So, qualitative analysis, such as localization of defaults in a building wall can today be performed quite easily.

However, passive IR thermography has also some disadvantages to carry out a quantitative analysis of the insulation of a building. The first one is that IR thermograms have to be corrected to obtain the true surface temperature. Indeed, the computation of the surface temperature of a wall must be done considering the influence of several parameters: emissivity of the surface $\varepsilon$, heat flux coming from the environment and reflected by the 
studied surface, atmospheric transmission factor $\tau$. This can be summarized by the following equation which described what is really measured by an IR camera, i.e. an intensity $L$ :

$$
L=\tau \varepsilon L^{\circ}\left(T_{0}\right)+\tau \rho L^{\circ}\left(T_{e n v}\right)+(1-\tau) L^{\circ}\left(T_{a}\right)
$$

In Eq. (1), we assume that the studied surface is an opaque perfectly diffusive surface that also behaves like a grey body in the spectral range of the camera. In Eq. (1), $\rho$ is the reflectivity of the surface, $T_{0}$ is the surface temperature, $T_{\text {env }}$ is the black-body equivalent temperature of the environment radiation and $T_{\mathrm{a}}$ is the atmospheric temperature. Some of the parameters in Eq. 1 can be estimated or measured with a quite good accuracy, like for instance $\tau$ and $T_{\mathrm{a}}$, and others are known only with important uncertainties and require the use of handbook or literature data or to perform additional specific measurements or investigations.

\subsection{Principle of the detection}

Passive IR Thermography can be used for the localization of building insulation defaults or for the estimation of the quantification of heat losses. In both cases, measurements have to be performed outside of the building and in the case where the inside temperature is greater than the outside one. So, this kind of measurements are commonly performed in winter during the night.

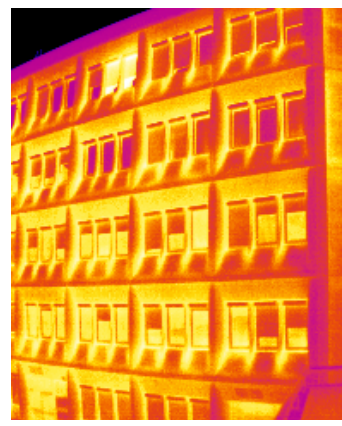

(a)

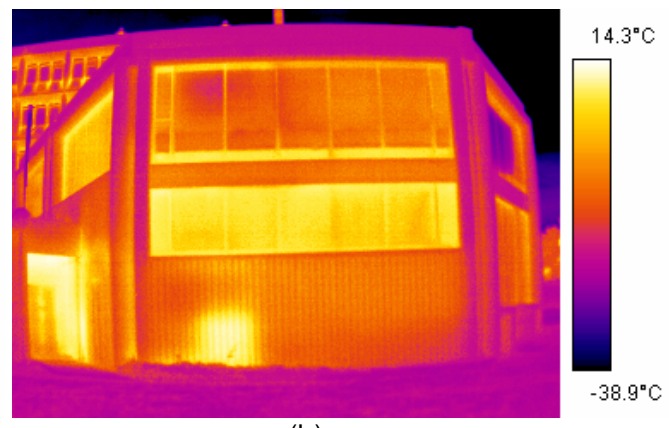

(b)

Fig. 1. Some examples of insulation defaults by passive IR thermography (see text for details).

The detection of insulation defaults can be done using only raw data obtained from the IR camera. However, it is necessary to carefully identify in the thermal scene, the regions of different emissivity, and also to take into account the possible influence of the reflected flux coming from the surrounding environment. Fig. 1 presents two examples of detection of insulation default. In Fig.1 (a), we can observe some losses between concrete plates in the right part of the building. We can observe also the reflection of a buiding in the glassy surfaces (also in the right part of the building). Again, some temperature differences are noted between windows : some are protected by a PVC shutters, others not. Fig. 1 (b) presents the IR thermogram obtained on a noninsulated wall. The position of a hot-water radiator can even be localized from the outside.

\subsection{Correction of temperature field}

To perform some quantitative analysis of passive IR thermograms, it is first necessary to correct IR thermograms. The most influencing parameter is often the IR flux reflected by the observed surface. The estimation of an equivalent black-body temperature of the surroundings can be performed using a diffusive mirror placed in the field of view of the camera. This method was proposed by S. Datcu et al. in the references $[1,2]$ and applied to the correction of temperature field in the case of inside and outside measurements. The application of this method to indoor measurements is presented in Fig. 2 (a) and to outdoor measurements in Fig. 2 (b) [1, 2].

Fig. 3 presents the vertical temperature profiles obtained from IR measurements along the vertical line in the center of the thermal scene presented in Fig. 2(a) (indoor measurements), before and after temperature correction [1]. The mean value of the temperature correction is here about $1.5^{\circ} \mathrm{C}$. Besides, corrected temperatures are close to the punctual temperature measurement performed using a surface thermocouple. The uncertainty on the corrected temperature was estimated equal to about $1^{\circ} \mathrm{C}$. This uncertainty takes into account individual uncertainties on the surface emissivity, on the calibration of the camera, on the emissivity of the diffusive mirror and on the mean equivalent black-body temperature of the surroundings. This low uncertainty value is mainly due to the fact that both emissivities of the wall surface and of the mirror were previously measured $[1,2]$ and also to the fact that measurements are performed in laboratory conditions.

A similar correction was done for the thermogram presented in Fig. 2(b) and results reported in [1]. Measurements were done during the night, with an atmospheric temperature $T_{\mathrm{a}}$ ranging from $12.3-13.6^{\circ} \mathrm{C}$, and at a distance of about $25 \mathrm{~m}$ from the building [1]. The mean black-body equivalent temperature of the surroundings was estimated to $T_{\text {env }}=7.4 \pm 1.1^{\circ} \mathrm{C}$. The temperature correction is about $0.5^{\circ} \mathrm{C}$ to $1.5^{\circ} \mathrm{C}$ in that case [1]. The mean uncertainty values obtained are about $1.1^{\circ} \mathrm{C}$ in the case of a mean surface temperature close to $15^{\circ} \mathrm{C}[1]$. 


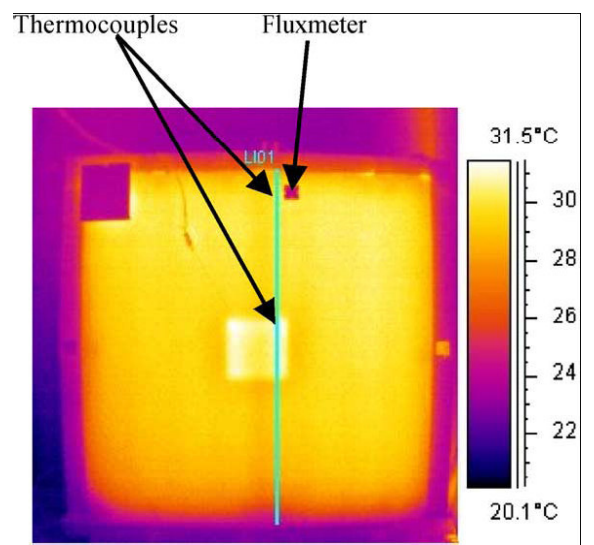

(a)

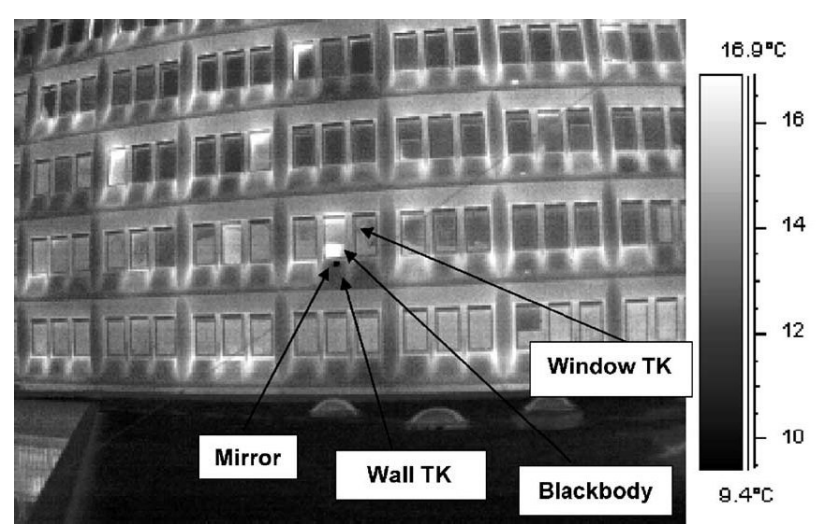

(b)

Fig. 2. (a) Indoor wall surface IR image and (b) outdoor IR image of a building of Paris 12 University [1].

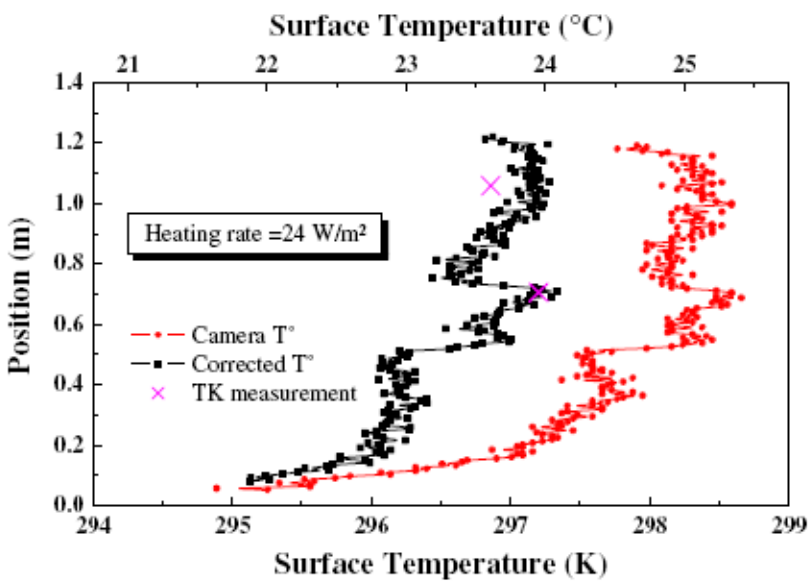

Fig. 3. Temperature profiles plotted on the vertical line of Fig. 3(a); comparison between uncorrected and corrected temperatures obtained from IR Thermography ; a thermocouple measurement was added for reference [1].

\subsection{Estimation of losses}

When the surface temperature $T_{0}$ of a wall has been corrected, it is possible to try to estimate the heat losses onto the wall surface. The heat flux density exchanged on the wall surface can be computed as follows:

$$
\phi_{\text {Total }}=\varepsilon \sigma\left(T_{0}^{4}-T_{e n v}^{4}\right)+h\left(T_{0}-T_{a}\right)
$$

This heat flux density is composed of two terms: the first one corresponds to radiative exchanges and the second one to convective exchanges. Parameters $T_{\mathrm{a}}, T_{\text {env }}$ and $\varepsilon$ in Eq. 2 are known because they were previously estimated for the correction of the surface temperature. The last parameter to take into account is the convective heat exchange coefficient $h$. This parameter can be estimated using literature correlations or sometimes estimated by an additional measurement.

An estimation of heat losses was performed for the experimental case corresponding to the thermogram of Fig. 2(a). The reference object, studied in that case, is made up of a multi-layer vertical wall with dimensions 1.20 $\mathrm{m} \times 1.20 \mathrm{~m}$ and $0.27 \mathrm{~m}$ thickness. The wall contains at the center a thermal insulation default and is heated using an electric heater film of about $1 \mathrm{~mm}$ thickness. Back and side faces of the wall are insulated with expanded to minimize the backward heat transfers. The experimental study reported in $[1,3]$ was performed for two heating powers of the wall embedded electrical heater: 24 and $48 \mathrm{~W} / \mathrm{m}^{2}$. Estimations of heat losses estimation along the vertical line in Fig. 2(a) using three distinct literature correlations [3] in the case of an heating power of $48 \mathrm{~W} / \mathrm{m}^{2}$ [3] are presented in Fig. 4(b).

A higher heat flux density is observed in the region corresponding to the position of the insulation default. Besides, estimated values are close to the power density used. Nevertheless, significant discrepancies are observed between curves obtained using the different correlations. Moreover, the uncertainties obtained are important (about 15\%). This uncertainty is only slightly depending on the power density. Indeed, a relative uncertainty of about $30 \%$ is observed when using a power density of $24 \mathrm{~W} / \mathrm{m}^{2}$ [3]. 


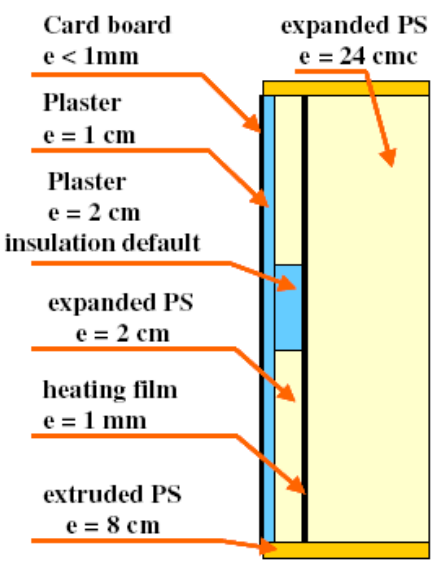

(a)

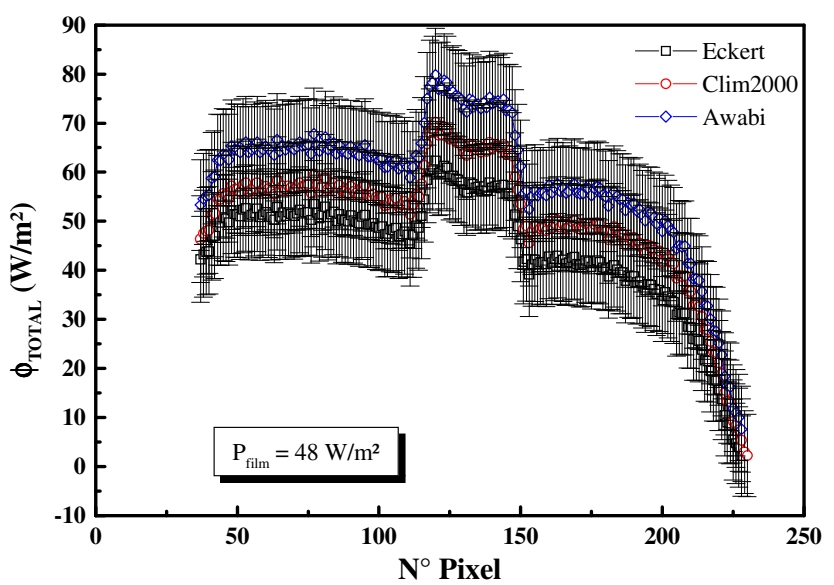

(b)

Fig. 4. (a) Schematic view of the wall structure; (b) : Estimation of heat losses (see text for details) [1,3].

\section{Active IR thermography}

\subsection{The experimental device implemented}

The experimental device implemented for this study is the System of Analysis of Thin Materials by Infrared Thermography (SAMMTHIR) of the Laboratory of Energetics and Optics of the Faculty of Science of Reims. It uses two halogen lamps as source of excitation. It uses an infra-red camera of thermography of A20 type from Flir as detector. It uses finally an electronics and a data processing to pilot the instrumentation, allowing a photothermic analysis (Fig. 5).

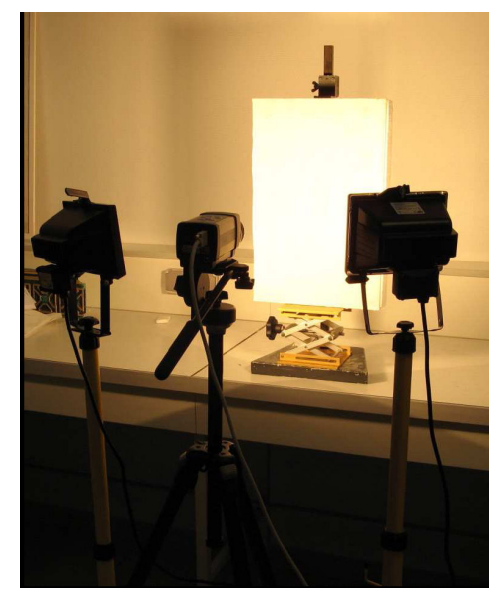

Fig. 5. The experimental device implemented.

\subsection{Studied samples and experimental results obtained}

The first sample that we studied is a plate of plaster facing of $13 \mathrm{~mm}$ thickness, on which some $6 \mathrm{~cm}$ thickness is fixed expanded polystyrene. In this sample we generated two complete absences of insulator. First is left such as it is, in order to study the possibilities of the photothermic method as regards detection of total lack of insulator. In second is sealed with the plaster, an electric sheath of Ordinary Rigid type Insulating (IRO) in order to approach the possibilities of the photothermic method as regards electric detection of raceway (Fig. 6).

The first sample that we studied is a plate of plaster facing of $13 \mathrm{~mm}$ thickness, on which some $6 \mathrm{~cm}$ thickness is fixed expanded polystyrene. In this sample we generated two complete absences of insulator. First is left such as it is, in order to study the possibilities of the photothermic method as regards detection of total lack of insulator. In second is sealed with the plaster, an electric sheath of Ordinary Rigid type Insulating (IRO) in order to approach the possibilities of the photothermic method as regards electric detection of raceway (Fig. 6).

The results are presented on Fig. 7. It represents for one, in coding false colors and for the other in threedimensional sight, the temporal integral of the infra-red images obtained within this framework. They both reveal an infra-red signature different at the place from the defects: Appearance of a blue band and a blue "square" in the first case and of a "ditch" and a "hole" in the second case. These characteristic signatures are due to the more insulating thermal properties polystyrene compared to the plaster and to the air filling the defects, because then subjected to losses by radiation and convection. Indeed our procedure consists in exciting our sample with visible 
light. This light, during an interaction matter radiation slightly heats the surface of the studied sample. This heating is propagated then by conduction in the sample. At the place of the lacks of polystyrene, this propagation was accelerated. It follows from there a faster cooling of lit surface to the right of the defects and thus a less important infra-red signature to this place.

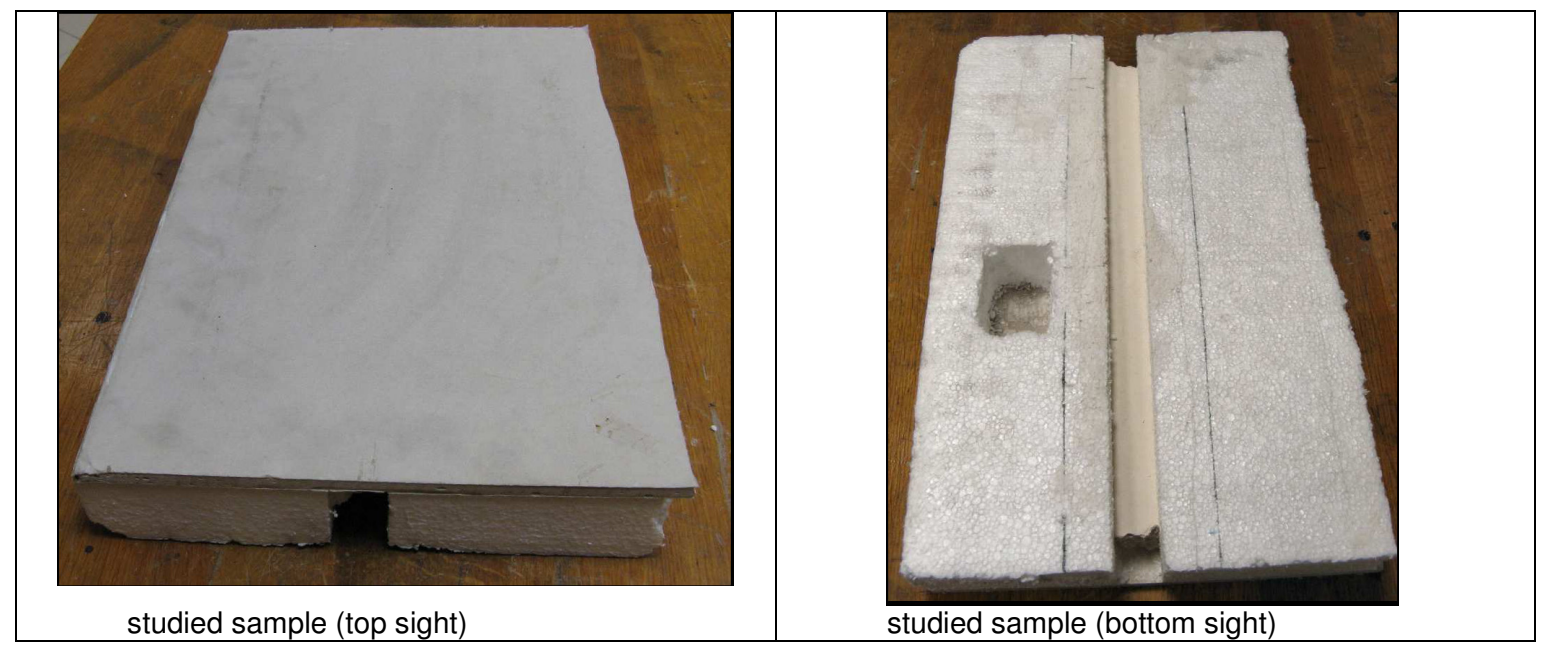

Fig. 6. The studied complex of plaster/polystyrene insulation presenting a total lack of insulator and the inclusion of electric Ordinary Rigid tube Insulating.

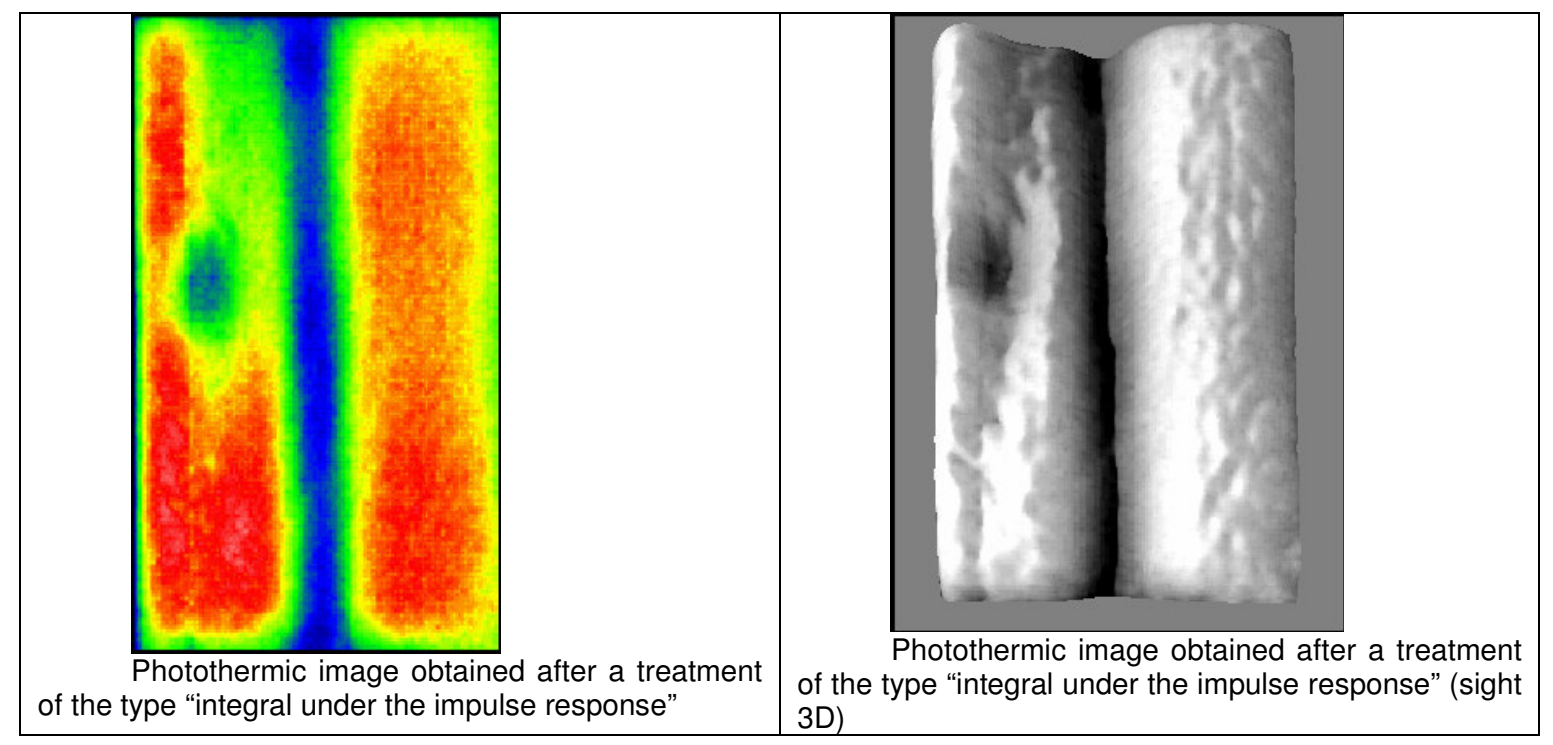

Fig. 7. Detection of a total lack of insulator and an electric Ordinary Rigid tube Insulating in a complex plaster/polystyrene by stimulated infra-red thermography
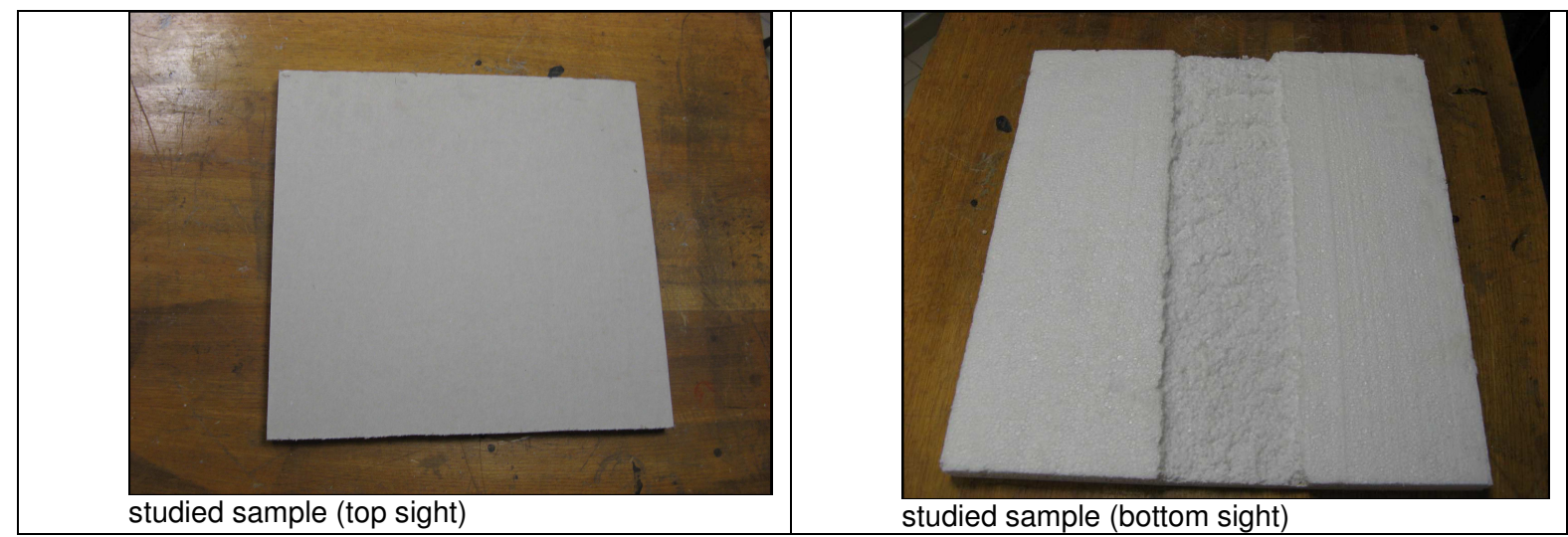

Fig. 8. The studied complex of insulation plaster /polystyrene presenting a lack partial of insulator 
Following this first study, showing the possibilities of the method as regards detection of total lack of insulator or inclusion of electric tube IRO, we wanted studied in the second time its possibilities as regards detection of maque partial of insulator. We then studied a new insulating complex composed of a plasterboard 13 $\mathrm{mm}$ thickness and of a layer of $2 \mathrm{~cm}$ thickness polystyrene, in which, we removed partly central sample a thickness from approximately $1 \mathrm{~cm}$ (Fig. 8).

The photothermic results then obtained are presented on Fig. 9. They show, in the same way that previously and because of the more insulating thermal properties of polystyrene compared to the air filling the lack of polystyrene, a less important photothermic signal at the place of the defect and thus the possibility of detecting a lack partial of insulator by photothermic radiometry.

In a third stage, it is the sensitivity of the photothermic method to a variable thickness of polystyrene which we wanted to approach. We then studied a complex isolating composed of a plasterboard from $13 \mathrm{~mm}$ thickness stuck to seven thicknesses of polystyrene different, variable from $0 \mathrm{~mm}$ to $6 \mathrm{~mm}$ per step of $1 \mathrm{~mm}$ (Fig. 10).

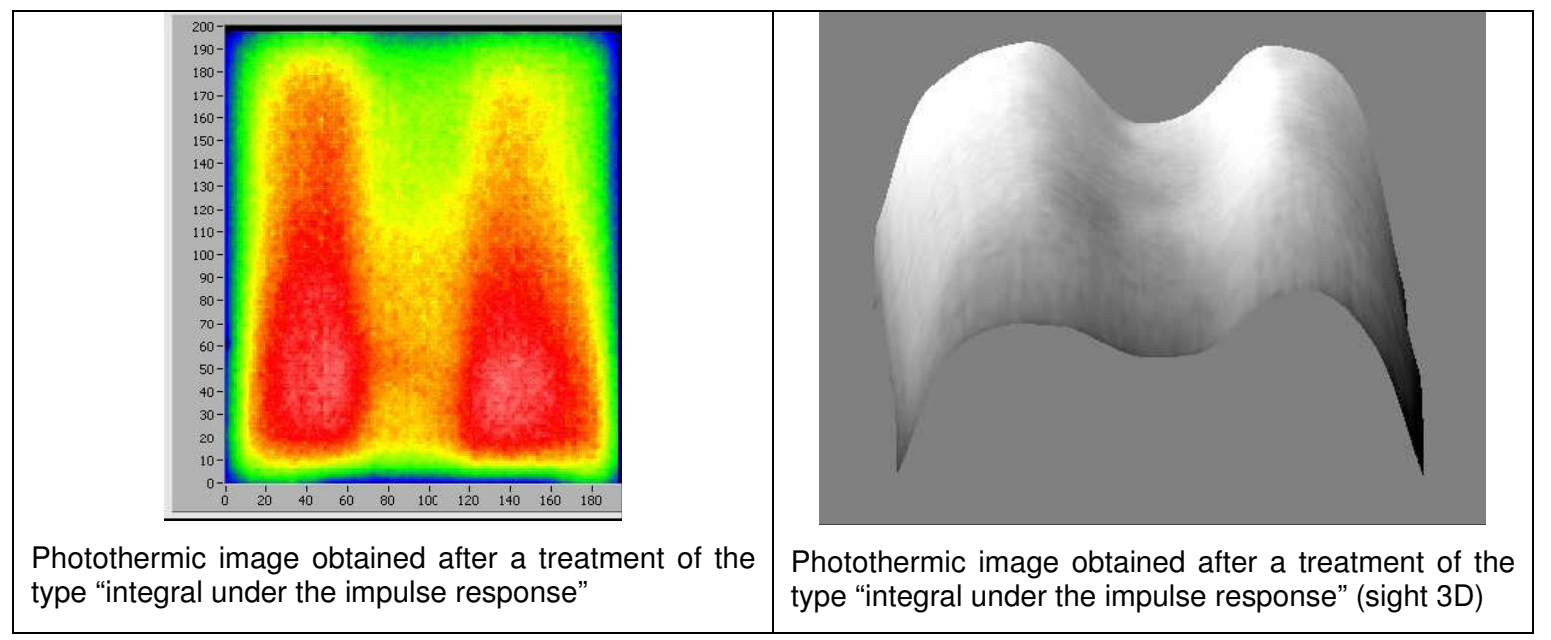

Fig. 9. Detection of a partial lack of insulator in a plaster/polystyrene complex (BA 13) by stimulated infrared thermography
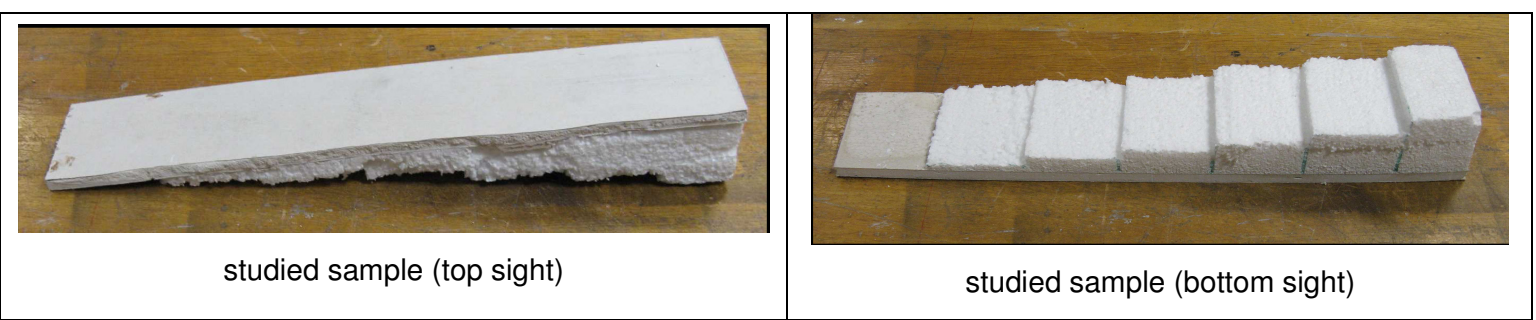

Fig. 10. The complex of plaster/polystyrene insulation having a variable thickness of studied insulator

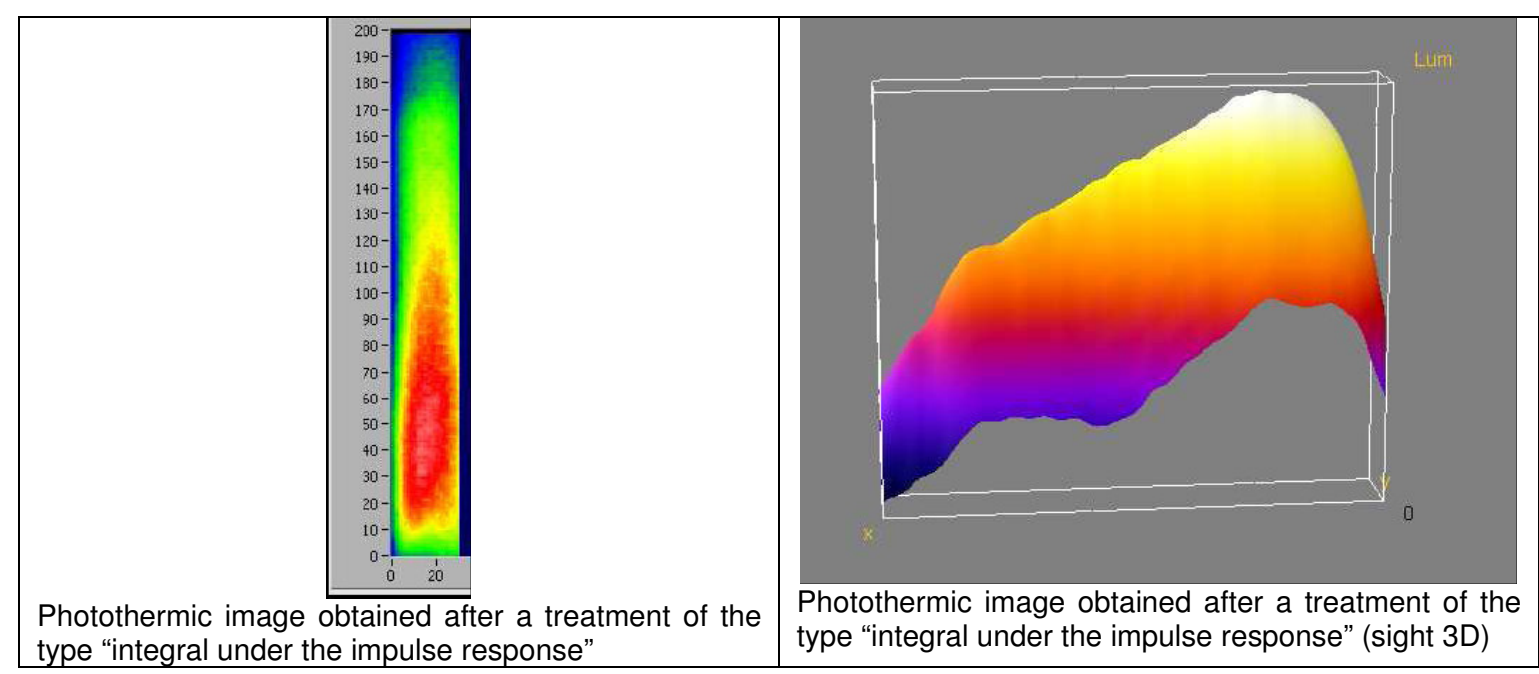

Fig. 11. Detection of a variation thickness of insulator in a plaster/polystyrene complex per stimulated infrared thermography 
The results obtained show clearly and for the same reasons as previously, the sensitivity of the photothermic method to a variation thickness of polystyrene and consequently the interest which it could present for an energy assessment of a dwelling (Fig. 11).

In a fourth stage, we wanted to partly approach the possibilities of the photothermic method as regards detection of lack of filled polystyrene have all by plaster. For that, we studied two samples. The first (sample A) is composed of a plate of placoplâtre covered 7 thicknesses of plasters different going from $0 \mathrm{~mm}$ to $3 \mathrm{~mm}$ per step from approximately $0,5 \mathrm{~mm}$. The second (sample B) consists of a block of polystyrene $5 \mathrm{~cm}$ thickness, of which the central part was dug continuously of $0 \mathrm{~mm}$ to $4 \mathrm{~mm}$ of depth, then filled with plaster (Fig. 12).

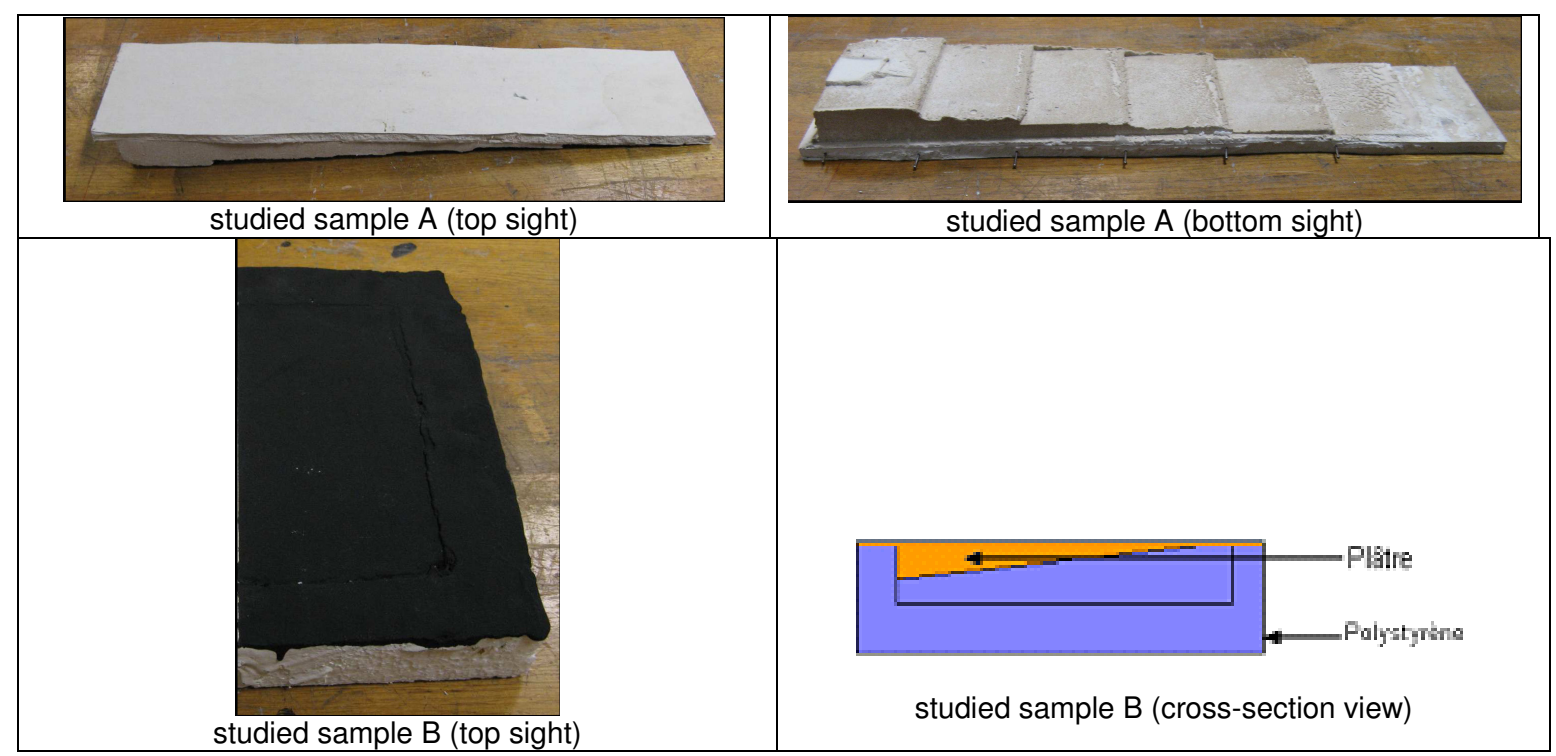

Fig. 12. Complexes of plaster/polystyrene insulation having a variable thickness of studied plaster.

The results obtained within this framework are presented on Fig. 13. They show that during a photothermic analysis and as for polystyrene, a variation thickness of plaster generates a modification of the internal heat transfers to the sample, detectable on the surface by infra-red optical way.

Lastly, the last studied sample is composed of a plate of placoplâtre on which two rails of assembly are fixed. The objective of this study was to approach the possibilities of the photothermic method as regards localization of the structure carrying a framework of insulation of the type "placostyle" (Fig. 14).

Results obtained within this framework thus presented on Fig. 15. They reveal more important photothermic signatures at the place of the screw fasteners and rails of the carrying structure (that one could allot, even if a more complete thermal study proves to be necessary, in the first case, with the higher absorptivity of metal constituting the screws and in the second case, with thermal resistance resulting from the imperfect contact between the placoplatre and the rail of support) and thus the possibility of detecting a structure carrying type "placostyle" by infra-red photothermic thermography.

\section{Conclusion}

In the first part of this paper, concerning passive IR Thermography, we showed that even all parameters to take into account for the estimation of heat losses in a wall surface are carefully estimated or measured, the uncertainties obtained remains too important to perform an accurate diagnosis of a building insulating default.

In the second part of this work, we approached the possibilities of the stimulated infra-red thermography like helps with the detection of defects of insulation in the field of the building. The process of insulation which was retained for this study is most representative of the French market and is composed of a plate of plaster facing on which is fixed expanded polystyrene. Among all the possible defects of insulation, we chose to study those which are most usually met in France.

Thus we initially showed that the method allows the detection of defects generated by a complete absence of insulator. We then showed that the method allows the detection of defects generated by an absence partial of polystyrene. Within this framework, we stressed that the method was sensitive to the thickness of insulator located behind the layer of placoplâtre and thus which it could be of a useful contribution within the framework of the establishment of the heat balance of a dwelling.

We still showed that the method allowed the detection of lacks of polystyrene filled in all or partly by plaster. What can be very useful, as we showed for the electric localization of raceway or there too within the framework of the establishment of energy assessments of dwellings. In a last stage, we showed that the method could help to find the structure carrying a complex of insulation of the type "placostyle".

It would be now interesting on the one hand, to study the possibilities of the photothermic method as regards quantitative analysis of the complex insulating placoplatre/polystyrene, in order to lead for example to the establishment of the energy assessment of a dwelling. It would be interesting in addition to study the possibilities 
of the method as regards qualitative and quantitative analysis of other modes of insulation. Studies going in this direction are in progress.

\section{Acknowledgement} France.

First part of this work was partly done thanks to a financial support from the R\&D department from EDF,

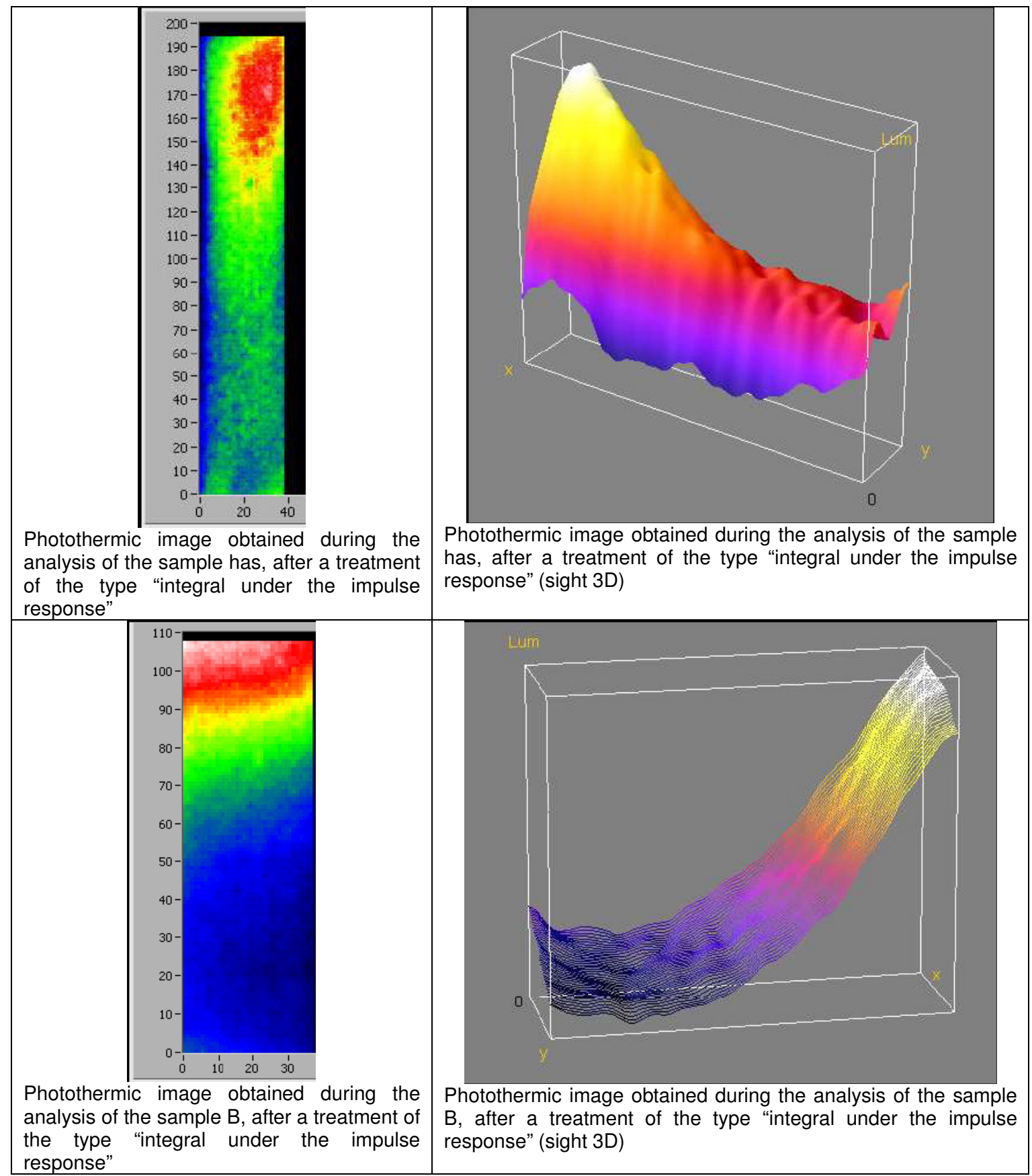

Fig. 13. Detection of a variation thickness of plaster in a Plaster/polystyrene complex by stimulated infrared thermography 


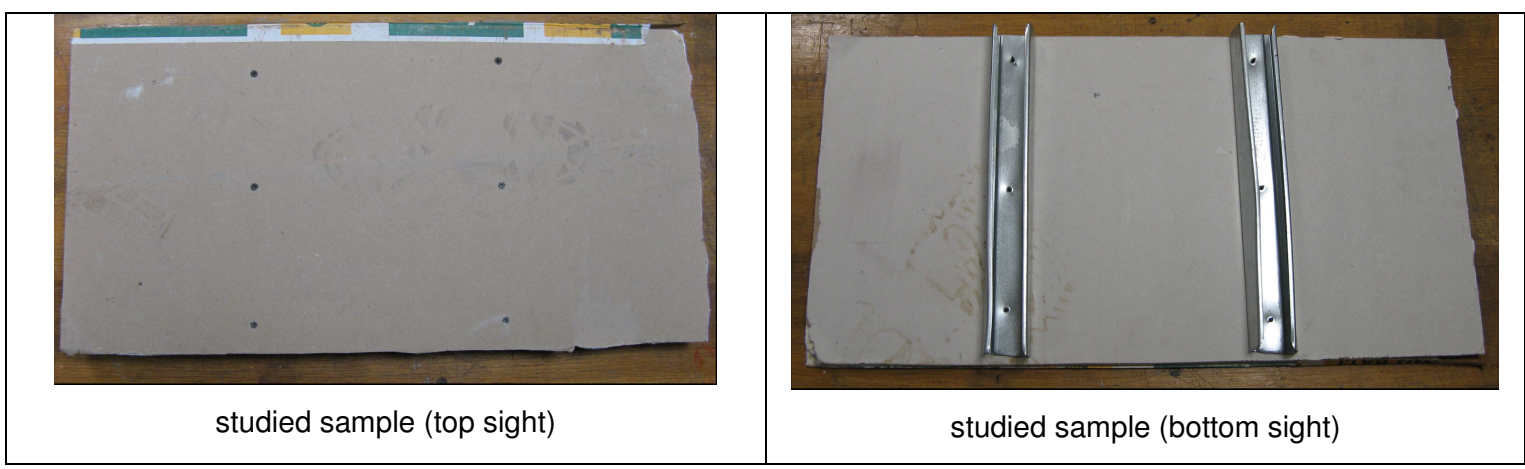

Fig. 14. The studied framework of the type "placostyle"

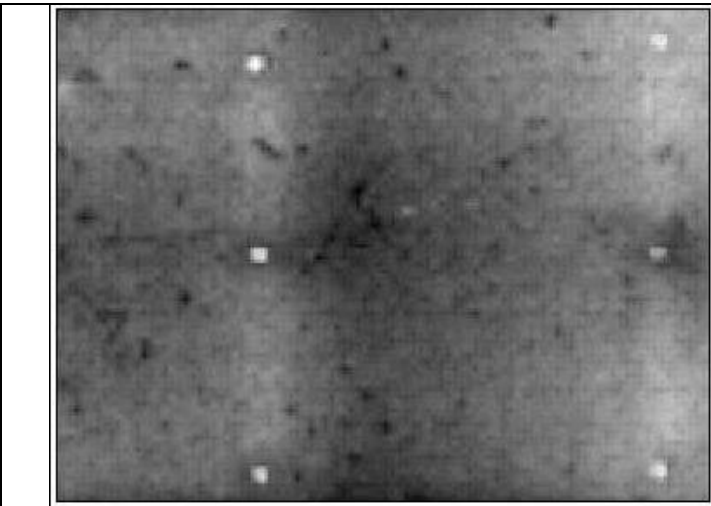

Photothermic image obtained after a treatment of the type "integral under the impulse response"

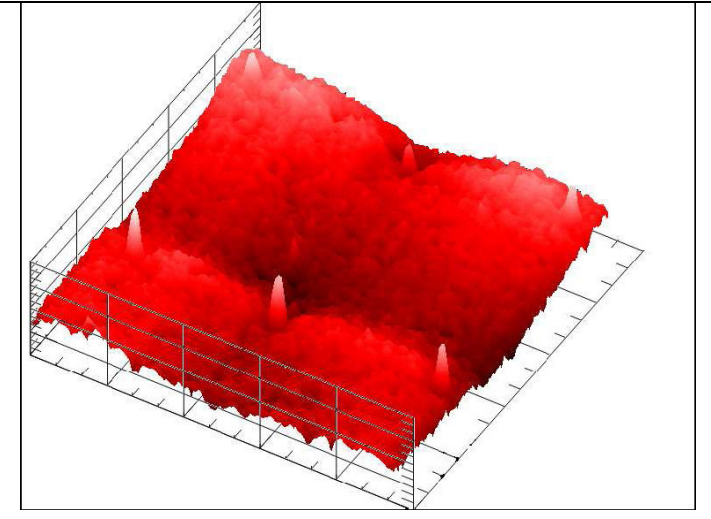

Photothermic image obtained after a treatment of the type "integral under the impulse response" (sight 3D)

Fig. 15. Detection of a structure "placostyle" through a layer of placoplâtre by stimulated infra-red thermography

\section{REFERENCES}

[1] S. Datcu, L. Ibos, Y. Candau, S. Matteï, Contribution to improvement of the building wall surface temperature measurements by infrared thermography, Infrared physics and Technology, 46 (2005) 451-467

[2] S. Datcu, L. Ibos, S. Mattei, J.-C. Frichet, Quantification of incident radiation on the building walls surfaces by means of infrared thermography, SPIE Vol. 4710, Thermosense XXIV, 2002, pp. 307-316

[3] S. Datcu, Quantification des déperditions thermiques des bâtiments par thermographir infrarouge, $\mathrm{PhD}$ Thesis, University Paris 12, Créteil, France, 2002

[4] B.Axen, D.Holmsten Swedish experiences in the application of thermography for establishing priorities and quality control in residential dwelling retrofits SPIE Vol. 254 Thermosense III, 1980, pp. 77-90

[5] J.B.Evans Metrology and infrared measurements SPIE vol. 254 Thermosense III, 1980, pp.21-23

[6] R.A.Grot Interpretation of thermographic data for the identification of building heat loss SPIE Vol. 254 Thermosense III, 1980, pp. 24-29

[7] D.T.Harrje, G.S.Dutt, K.J.Gadsby Isolating the building thermal envelope SPIE Vol. 254 Thermosense III, 1980 , pp. $50-56$

[8] H.Kaplan Infrared thermal sensing and how we use it SPIE Vol. 254 Thermosense III, 1980, pp. 2-8

[9] J. Lang, M.Stani Thermographic inspection of buildings in Austria SPIE Vol. 313 Thermosense IV, 1981, pp. 45-49

[10] L. Youcef, L. Ibos, J.L. Bodnar, S. Oblin, A. Mazioud, S. Datcu, Y. Candau, J-C Frichet et P. Richard, Analyse thermique de complexes isolants par thermographie infrarouge, Actes CMOI 2006, Mulhouse.

[11] S. Oblin, P. Richard, J.L Bodnar : Thermographie infrarouge stimulée appliquée à la détection de défauts d'isolation dans le bâtiment. Proceeding of the International symposium on building systems and technologies for energy conservation. 15 - 16 mai 2000, Lasi (Roumanie), pp 15-20. 
http://dx.doi.org/10.21611/qirt.2008.05_01_08 